\title{
CARACTERIZAÇÃO AMBIENTAL: GEOLOGIA, GEOMORFOLOGIA E SOLO NO BAIXO CURSO NA BACIA DO RIO CABAÇAL EM CURVELÂNDIA MATO GROSSO
}

\author{
Cristiane da Silva Lima ${ }^{(a)}$, Thales Ernildo de Lima ${ }^{(b)}$, Célia Alves de Souza ${ }^{(c)}$, José \\ Lourenço Alves da Silva ${ }^{(\mathrm{d})}$
}

\begin{abstract}
${ }^{(a)}$ Mestranda do Programa de Pós Graduação em Geografia, Universidade do Estado de Mato Grosso, cristiane-silva89@hotmail.com

${ }^{(b)}$ Graduando do Curso de Geografia, Universidade do Estado de Mato Grosso, lima.thales@outlook.com

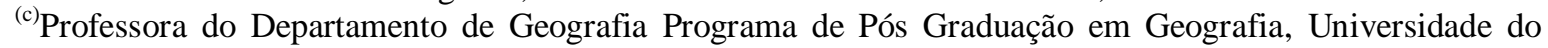
Estado de Mato Grosso, celiaalvesgeo@ globo.com

(d) Mestrando do Programa de Pós Graduação em Geografia, Universidade do Estado de Mato Grosso.jose.geo.alves@ hotmail.com
\end{abstract}

\section{EIXO: BACIAS HIDROGRÁFICAS E RECURSOS HÍDRICOS: ANÁLISE, PLANEJAMENTO E GESTÃO}

\begin{abstract}
Resumo
O estudo teve como objetivo realizar levantamento das características ambientais, Geologia, Geomorfologia e Solo no baixo cursodo rio Cabaçal, afluente da margem esquerda do rio Paraguai. As informações foram obtidas nos relatórios o projetoRadambrasil e confirmação no campo. Para compilação dos mapas temáticos as ferramentas do software ArcGis 10.1. Registrou as seguintes ocorrênciasgeológicas: Formação Pantanal(área 423,21 km²)e aluviões atuais(área $2888,54 \mathrm{~km}^{2}$ ), possui duas unidades geomorfológicas a Depressão do Alto Paraguai (área $\left.48.74 \mathrm{~km}^{2}\right)$ e a Planície do rio Cabaçal $\left(a\right.$ rea $\left.240,74 \mathrm{~km}^{2}\right)$. As classes solos presente são osNeossolosQuartzarenoOrticoTípico(área130,09km²), Latossolo Vermelho Amarelo Distrófico Típico(área 309,62 km²)e GleissoloHaplico Tb EutroficoTípico(área 272,02km²).
\end{abstract}

Palavras-chave: Caracterização ambiental; rio Cabaçal; baixo curso.

\section{Introdução}

Cunha (1998) considera que a bacia hidrográfica é uma unidade geomorfológica importante por agrupar e interagir vários fatores, tais como: bióticos, abióticos, econômicos e sociais. As bacias hidrográficas interagem numa visão de conjunto, ressaltando-se as condições naturais e as atividades humanas nelas desenvolvidas. Intervenções expressivas, principalmente de origem antrópica em qualquer parte de uma bacia podem gerar alterações, cujos impactos serão transferidos a jusante, influenciando no fluxo energético e na dinâmica fluvial.

Segundo Suguio e Bigarella (1990), os elementos físicos ambientais: climático, recobrimento florestal, bem como, a capacidade de infiltração (solo), influência geológica e geomorfológica influenciam diretamente no condicionamento do escoamento superficial (deflúvio) em uma bacia hidrográfica, indicando a quantidade total das águas das precipitações que alcançam o canal fluvial. 


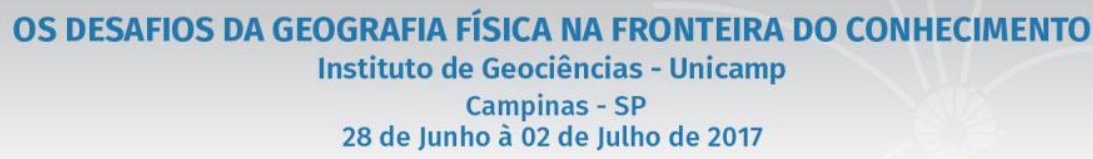

Os elementos que compõem as características ambientais de uma determinada bacia hidrográfica não são isolados. O relevo é apenas um de seus integrantes e está relacionado com as rochas que o sustenta, com o clima que o esculpe e com os solos que o recobre. Através de uma ação simultânea, embora de forma desigual, ao longo do tempo e do espaço todos se modificam continuamente, influenciando e sendo influenciados. Desse modo, através de estudos ambientais, os resultados servem de indicadores às potencialidades dos recursos naturais e, ao mesmo tempo, às fragilidades locais (ROSS, 2009).

Para Marques (2008), os estudos geomorfológicos possuem uma importância fundamental no desenvolvimento de trabalhos teóricos e práticos, podendo ser utilizados em diagnósticos, impactos ambientais, monitoramentos, planejamentos, gerenciamentos, gestões e prognósticos ambientais, oferecendo condições na identificação e interpretação das múltiplas relações do objeto de estudo com os demais elementos do ambiente.

O levantamento das características ambientais que compõem uma bacia hidrográfica é um instrumento de pesquisa que permite conhecer a sua estrutura e funcionamento. Os resultados desses estudos são bons indicadores do potencial de recursos naturais que a bacia pode oferecer, bem como o apontamento das suas fragilidades (ROSS, 2009). Estas características, em uma bacia, estão relacionadas aos aspectos geológicos, às formas de relevo, aos processos geomorfológicos e às características hidrológicas e climáticas, assim como à biota e à ocupação da Terra (TORRES et al., 2012).

Estudos realizados por Avelino(2006)destaca que a Bacia Hidrográfica do rio Cabaçal possui suas nascentes na Chapada dos Parecis, com área de $6.042 \mathrm{~km}^{2}$. Percorrendo um trecho de depressão no alto e médio curso; no baixo curso, envolve área de planície, próxima da confluência com rio Paraguai. Tendo como principais afluentes:Rio Branco, Rio Vermelho e Rio dos Bugres.

O estudo teve como objetivo realizar levantamento das características ambientais, Geologia, Geomorfologia e Solo no baixo cursodo rio Cabaçal, afluente da margem esquerda do rio Paraguai, Mato Grosso.

\section{Materiais e Métodos}

\section{Área de estudo}

A área de estudo corresponde ao baixo curso da bacia do rioCabaçalque está localizada entre as coordenadas geográficas $15^{\circ} 28^{\prime} 17.30^{\prime \prime}$ a $16^{\circ} 2^{\prime} 10.30^{\prime \prime}$ Latitude Sul e a $57^{\circ} 57^{\prime} 54.30^{\prime \prime}$ a $57^{\circ} 36^{\prime}$ 22.30" Longitude Oeste (Figura 1). 


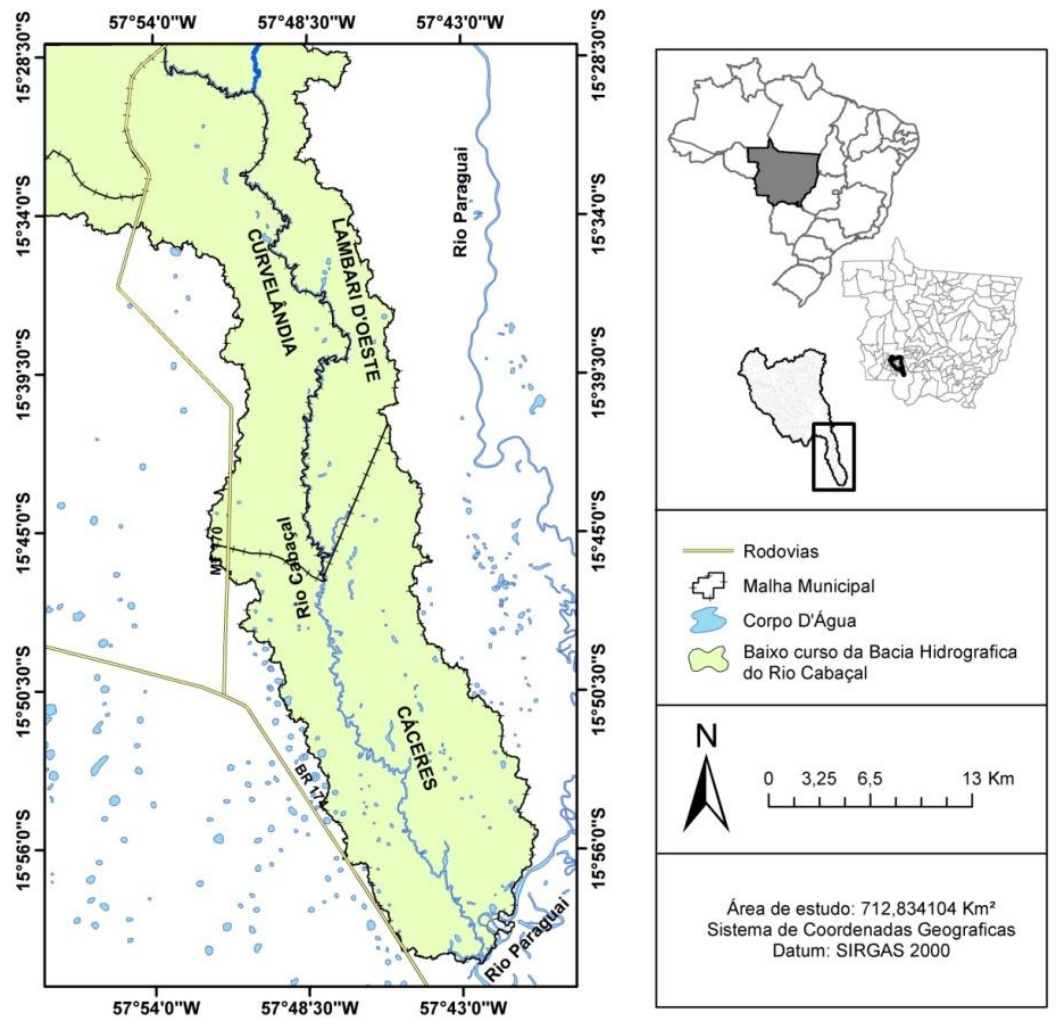

Figura 1- Localização do baixo curso da bacia hidrográfica do rio Cabaçal

\section{Procedimentos Metodológicos}

\section{Mapa de localização e temáticos}

Foram realizados trabalhos de caráter bibliográfico, que, de acordo com Gil (2002) e Marconi e Lakatos (2009), constituiu-se de levantamentos de materiais elaborados principalmente por livros e artigos de cunho científico, também foram realizados a confecção de mapas temáticos.

As informações sobre as condições ambientais da bacia no que se referem ao clima, geologia, geomorfologia, formações vegetais e solo, foram levantadas através de consultas bibliográficas, elaboração de mapas temáticos e visitas in loco. Foram analisadas as cartas topográficas de Cáceres e Rio Branco do Ministério do Exército em escala 1:100.000 que subsidiaram a leitura referente à sua localização no contexto geomorfológico. Os mapas temáticos foram elaborados a partir das informações do Projeto RADAMBRASIL (1982) com auxílio do softwareArcGis, versão 10.1 com imagens de satélite LANDSAT TM5 e TM8 em escala 1:100.000 com o intuito de obter informações acerca dos elementos ambientais que compõem a bacia.

As visitas in loco permitiram a observação direta da área de estudo e a comparação dos resultados obtidos através das imagens de satélite. 


\section{Resultados e Discussão}

De acordo com Tarifa (2011) o baixo curso do rio Cabaçalé constituída pelamicro-unidade climática regional denominado Tropical Megatérmico Úmido. As temperaturas mínimas anuais variam de $19,7^{\circ}$ a $20,5^{\circ} \mathrm{C}$ e as máximas de $32,1^{\circ}$ a $32,4^{\circ} \mathrm{C}$. A precipitação média anual é de 1.600 a 1.800 mmcom deficiência hídrica moderada de 250 a $300 \mathrm{~mm}$ nos meses de seca (maio a setembro). Os maiores índices de pluviosidade iniciam no mês de novembro, estendendo-se até abril, quando ocorre de pequeno a moderado excesso de 400 a $600 \mathrm{~mm}$ no balanço hídrico.

\section{Geologia}

No baixo curso da bacia hidrográfica, registra a ocorrência, Formação Pantanal(área423,21 km²), Aluviões indiferenciados ou antigos (área 17,45km²) e Aluviões atuais (área $2888,54 \mathrm{~km}^{2}$ )(figura 2).

De acordo com Corrêa e Couto (1972) a Formação Pantanal é constituída de uma sequência argilo-arenosa inconsolidada, estratificada horizontalmente, formada por uma alternância de argila cinza e areia média a fina, de cor branca, amarela e vermelha, com classificação regular a boa. Além do quartzo, as areias possuem conteúdo regular de caulim. Entremeados às camadas argilosas e arenosas, são localizados leitos laterizados de pequena espessura de areias e conglomerados finos.

Almeida (1964) diz que, os depósitos da Formação Pantanal são poucos espessos, com a composição areno-argilosos e síltico-argilosos, com granulometria predominantemente fina ou muito fina, ocorrendo também areias médias a conglomeráticos. Os grãos de quartzo são subarredondados e arredondados, as superfícies polidas com intercalações de níveis argilosos, tendo a fração cascalho, o resultado da movimentação ou dinâmica atual dos rios.

Os Aluviões indiferenciados ou antigos são encontrados em relevos planos e pouco dissecados são depósitos de terraços em planície aluvial e inclui-se também canais abandonados ou colmatados. É uma unidade que se constitui litologicamente por depósitos poucos espessos e é composto por areia, siltes, argilas e cascalhos. Esses depósitos apresentaram uma dinâmica de comportamento em seus agentes deposicionais e foram a relacionados com balanço da oscilação Climática ou fenômeno tectônico (RADAMBRASIL, 1982).

São constituídos por areia, silte, argilas e cascalhos sendo formado por desagregação das rochas existentes e são depositados nas planícies de inundação, apresentando espessura de $2 \mathrm{~m}$ em média apresentando formas típicas de planície aluvial como ilhas aluviares, diques marginais, meandros, lagoas e barra em pontal (BAP, 1997). 


\section{OS DESAFIOS DA GEOGRAFIA FÍSICA NA FRONTEIRA DO CONHECIMENTO \\ Instituto de Geociências - Unicamp \\ Campinas - SP \\ 28 de Junho à 02 de Julho de 2017}

Os aluviões atuais correspondem aos materiais inconsolidados que se encontram em deposição nos terraços e nas planícies fluviais no baixo curso da bacia hidrográfica do córrego Cachoeirinha próximo a confluência com o rio Paraguai.

A origem dos aluviões atuais relaciona-se à dinâmica dos períodos de cheia do rio Cabaçal, quando o rio transbordam águas e sedimentos, depositando-os na planície de inundação.

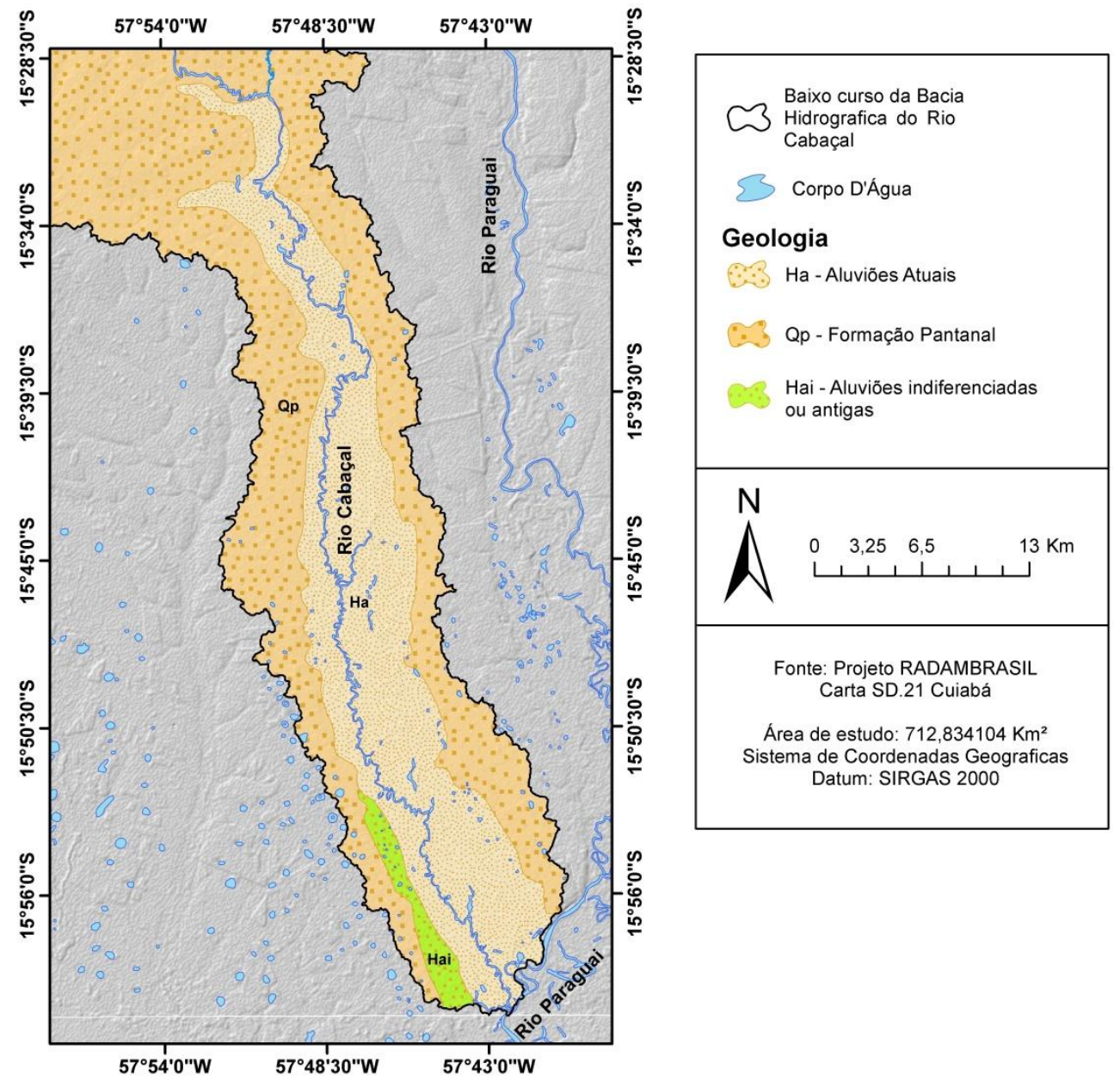

Figura - Ocorrência geológica no baixo da bacia hidrográfica do rio Cabaçal

\section{Geomorfologia}

Baixocurso destacam-se a Depressão do Alto Paraguai(área $48,74 \mathrm{~km}^{2}$ ), e planície do rio Cabaçal(área240,74 km²). A Depressão do Alto Paraguai e planície do rio Cabaçalpossuem altitudes baixas de 150 a 300 metros(figura 3 ). 

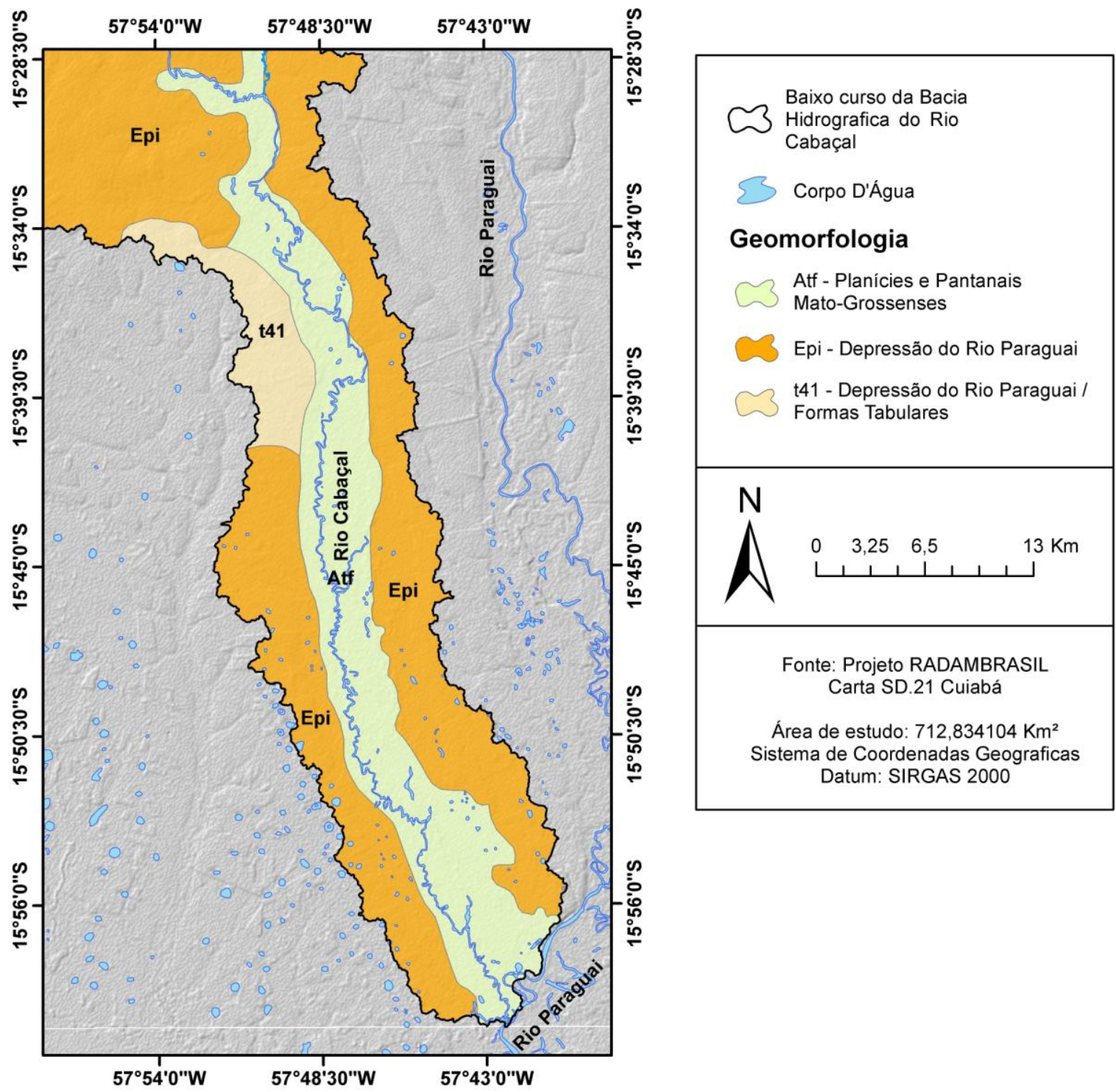

Figura 3 - Unidades geomorfológicas no baixo da bacia hidrográfica do rio Cabaçal

\section{Depressão do Rio Paraguai}

A Depressão do rio Paraguai é uma unidade é geomorfológica é originado por resquícios de acumulação marinha e é caracterizado por apresentar relevos baixos e tem como característica áreas que apresenta grandes áreas rebaixadas e drenadas pelos tributários (RADAMBRASIL, 1982).

Para Ross e Santos (1982), a subunidade de relevo compreende a uma extensa área drenada pelo rio Cabaçal. Envolve uma superfície de relevo pouco dissecado com pequeno caimento topográfico de norte a sul, apresentando-se rampeada em sua seção oeste com altimetria oscilante entre 120 e 300 metros. 


\section{Planícies e Pantanais mato-grossenses}

Essa unidade se encontra entre 80 a 150 altitudes constituídas por acumulação de depósitos de sedimentos carregados através do rio que possuem nascentes nos planaltos, serras e depressões que a circundam.

As configurações morfológicas da planície estão associadas ao padrão de canal (meandrante), sazonalidade (estiagem e cheias) a baixa declividade do terreno; a carga de sedimentos que são transportadas pelo rio principal e o uso da terra na bacia. Os gradientes são baixos nas áreas de planície, alterando constantemente com formação de feições morfológicas.

A planície em sua configuração espacial é composta por algumas feições: tais, como: lagoas, baías, depósitos de canais (barras centrais e ilhas fluviais de acumulação), depósitos de margens de canais (barras laterais) e depósitos de planícies de inundação (diques e cordões marginais)

As lagoas encontradas no baixo curso possuem formas circular, subcirculares e compostas (não apresentam uma forma definida e são combinações de outras classes). As diferentes formas de lagoas estão associadas ao aporte de sedimentos fornecido pelo rio Cabaçal e o processo de sedimentação na planície de inundação.

\section{Solos}

As classes solos presente no baixo curso da bacia hidrográfica são os NeossolosQuartzarênicosórticotipico(área130,09 $\mathrm{km}^{2}$ ), Latossolo Vermelho Amarelo Distrófico Tipico(área 309,62 $\mathrm{km}^{2}$ )e GleissoloHaplicoTbEutroficoTipico(área272,02km²)(figura 4). 


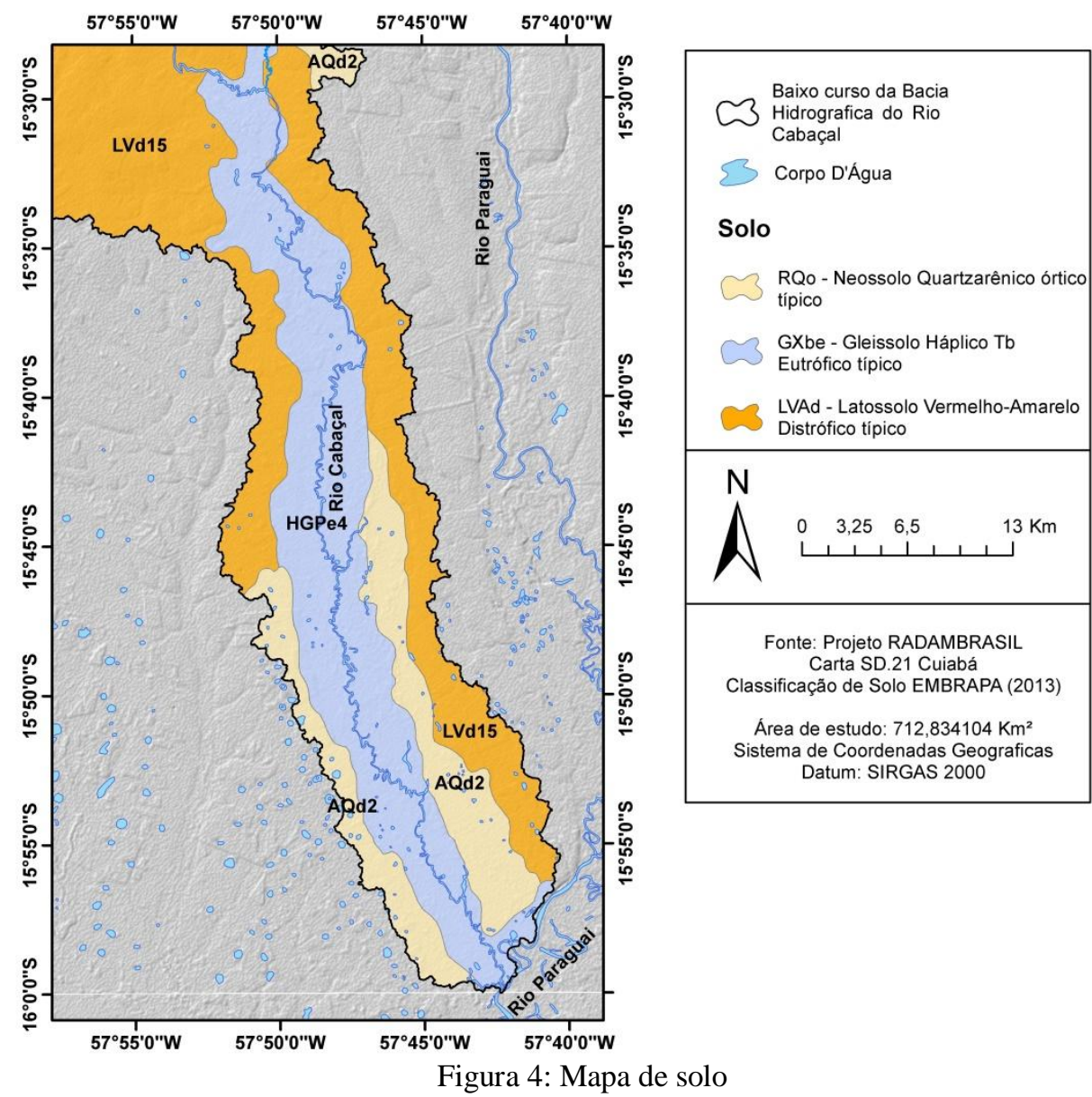

OsNeossolosQuartzarênicos correspondem a 18,28\% dos solos da área de estudo, são encontrados em três manchas. Suas características físicas aliadas ao uso sem adotar as técnicas corretas de manejo potencializa o surgimento de processos erosivos que vão desde pequenos sulcos até mesmo grandes voçorocas.

Os Neossolos são poucos evoluídos, não possuem horizonte B diagnóstico. Praticamente não se vê diferenciação entre os horizontes, com individualização do horizonte $\mathrm{A}$, seguido dos horizontes C ou R. Os Quartzarênicos são solos arenosos (BATISTA; PAIVA e MARCOLINO, 2014).

Tendo como característica não possuir contato lítico dentro de $50 \mathrm{~cm}$ de profundidade, este tipo de solo tem como sequência de horizontes A-C. Possui textura areia ou areia franca em todos os horizontes, sendo, essencialmente quartzosos possuem na fração areia grossa e fina $95 \%$ ou mais de quartzo, calcedônia e opala. O terceiro e quarto nível categórico como sendo Órtico e típico se caracterizam por não se enquadrar em nenhuma categoria apresentada a esse tipo de solo (SANTOS etal., 2014).

\section{Latossolo Vermelho Amarelo DistróficoTípico}


O solo está presente em $43,50 \%$ da área de estudo. Os Latossolos em geral apresentam horizonte subsuperficial uniforme em cor, textura e estrutura (horizonte B latossólico). São profundos, geralmente pobres, ocupando as superfícies mais velhas e estáveis da paisagem. A intensa intemperização dos constituintes minerais ocasionam maior concentração relativa de argilo-minerais resistentes. Possuem textura variável, média a muito argilosa, porosos, macios e permeáveis, pequena diferença no teor de argila em profundidade e são de baixa fertilidade natural (BATISTA, PAIVA e MARCOLINO, 2014).

Os latossolos em sua definição tem constituição mineral, possuem horizonte B latossólico procedido de qualquer horizonte A. O LATOSSOLOS VERMELHOS Distróficos argissólicos são solos intermediários para Argissolos e/ou apresenta em alguma parte do horizonte B (exclusive BA), estrutura em blocos moderada e cerosidade pouca e fraca dentro de $200 \mathrm{~cm}$ a partir da superfície do solo (SANTOS et al., 2014).

\section{GleissoloHaplico TbEutróficoTípico}

O GleissoloHáplico Tb EutróficoTípicoé caracterizado por apresentar forte gleização em virtude do regime de umidade redutor que se forma nos meios anaeróbicos originados de encharcamentos periódicos ou constantes. Apresenta sequência de horizontes do tipo $\mathrm{A}, \mathrm{Cg}$, com ou sem descontinuidade litológica, sendo o horizonte A do tipo moderado. A sua ocorrência se limita as áreas deprimidas sujeitas às inundações e às margens de curso de água, relacionados a sedimentos recentes do período Quaternário (OLIVEIRA et al., 1982).

Para Oliveira et al. (1982), o GleissoloHáplicoTbEutrófico é um solo profundo, mal drenado, de baixa permeabilidade com características físicas e químicas muito variadas, especialmente devido à natureza do material de origem, como também à distância do regime hídrico destas áreas.

Conforme Guerra e Botelho (2009), este tipo de solo não é suscetível ao processo erosivo pluvial, por situar-se em uma área plana e de baixa amplitude hipsométrica que não favorece ao rápido processo de escoamento pluvial superficial.

\section{Considerações Finais}

$\mathrm{Na}$ caracterização da geomorfologia, geologiae solo do baixo curso do rio Cabaçal. Observa que o trecho possui três ocorrências geológicas: aFormação Pantanal, Aluviõesindiferenciados ou antigos e Aluviões atuais. Quanto o relevo registrou duas unidades morfológicas: a Depressão do Alto Paraguai Planícies e Pantanais mato-grossenses. Com três classes de solos: NeossolosQuartzarenoOrtico Típico, Latossolo Vermelho Amarelo Distrófico Típico eGleissoloHaplico Tb EutroficoTípico. 


\section{REFERÊNCIAS BIBLIOGRÁFICAS}

28 de Junho à 02 de Julho de 2017

ALMEIDA, F. F. M. Geologia do Centro-oeste Mato-grossense. Boletim da Divisão de Geologia e Mineralogia. Rio de Janeiro, 1964. p.1-133.

AVELINO, P. H. M. Análise Geo-Ambiental Multitemporal para fins de Planejamento Ambiental: Um exemplo aplicado à Bacia Hidrográfica do Rio Cabaçal, Mato Grosso - Brasil. Universidade Federal do Rio de Janeiro. Rio de Janeiro, p. 317. 2006.

BATISTA, M. de A.; PAIVA, D. W. de; MARCOLINO, A. (Org.). Solos para todos: perguntas e respostas. Rio de Janeiro: Embrapa Solos, 2014. 87 p. (Embrapa Solos. Documentos, 169).

BRASIL. (1982). Ministério de Minas e Energia. Secretaria Geral. Projeto RADAMBRASIL. Levantamentos dos Recursos Naturais, Folha SD 21. Cuiabá, Rio de Janeiro: Secretaria Geral. 448 p.

CORREA, J. A.; COUTO, E. A. Projeto aluviões diamantíferos de Mato Grosso. 2 vol. Relatório Final. Goiânia: DNPM/CPRM, 1972.

CUNHA, S. B. Bacias hidrográficas. In: CUNHA, S. B.; GUERRA, A. J. T. (Orgs.). Geomorfologia do Brasil. Rio de Janeiro: Bertrand do Brasil, 1998. p. 229 - 265.

GIL, ANTONIO CARLOS. Como Elaborar Projetos de Pesquisa. 4 ed. São Paulo: Atlas, 2002. 173p.

GUERRA, A. J. T.; BOTELHO, R. G. M. Erosão dos solos. In: CUNHA, S. B.; GUERRA, A. J. T. (Orgs.). Geomorfologia do Brasil. 5 ed. Rio de Janeiro: Bertrand Brasil, 2009. p. 181 - 227.

LAKATOS, E. M.; MARCONI, M. de A. Fundamentos de Metodologia Científica. $5^{\text {a }}$ edição, São Paulo: Editora Atlas S. A. 2009. 310 p.

MARQUES, S. M. Ciência Geomorfológica. In: GUERRA, A. J. T.; CUNHA, S. B. (Orgs.). Geomorfologia: uma atualização de bases e conceitos. 8 ed. Rio de Janeiro: Bertrand Brasil, 2008. p. 23 - 50.

OLIVEIRA, V. A.; AMARAL FILHO, Z. P.; VIEIRA, P. C. Pedologia: levantamento exploratório de solos. In: BRASIL. Ministério das Minas e Energia. Secretaria Geral. Projeto RADAMBRASIL. Folha SD. 21 - Cuiabá: Geologia, Geomorfologia, Pedologia, Vegetação e Uso potencial da terra. Rio de Janeiro, 1982. p. 257 - 400.

Plano de Conservação da Bacia do Alto Paraguai -PCBAP/Projeto Pantanal, programa Nacional do Meio Ambiente ,Brasilia:PNMA,1997.3vol.em 7t.il,fig;fig; mapas

RADAMBRASIL. Mapa geológico: Mapa realizado para o programa da integração nacional. Rio de Janeiro, 1982.

ROSS, J. L. S. (2009) Geomorfologia ambiental. In: CUNHA, S. B.; GUERRA, A. J. T. (Orgs.). Geomorfologia do Brasil. 5 ed. Rio de Janeiro: Bertrand Brasil. p. $351-388$.

ROSS, J. L. S.; SANTOS, L. M. Geomorfologia. In: BRASIL. Ministério das Minas e Energia. Secretaria Geral. Projeto RADAMBRASIL. Folha SD. 21 - Cuiabá: Geologia, Geomorfologia, Pedologia, Vegetação e Uso potencial da terra. Rio de Janeiro, 1982. p. 193 - 256.

SANTOS, H. G. et al. Sistema Brasileiro de Classificação de Solos. 4. ed. Brasília, DF: Embrapa, 2014.

SUGUIO, K.; BIGARELLA, J. J. Ambiente fluvial. 2 ed. Florianopolis: ed. UFSC, 1990. 183 p.

TARIFA, J. R. Clima: análise e representação cartográfica. In: Mato Grosso - Secretaria de Estado de Planejamento e Coordenação Geral. Recursos naturais e estudos ambientais. Cuiabá-MT: Entrelinhas, 2011. $102 \mathrm{p}$.

TORRES, F.T.P.; NETO, R.M.; MENEZES, S.O. (2012) Introdução à Geomorfologia. São Paulo: Cengage Learning. 